\title{
Adaptive fractional integral terminal sliding mode power control of UPFC in DFIG wind farm penetrated multimachine power system
}

\author{
P. K. Dash ${ }^{1 *}$, R. K. Patnaik ${ }^{2}$ and S. P. Mishra ${ }^{1}$
}

\begin{abstract}
With an aim to improve the transient stability of a DFIG wind farm penetrated multimachine power system (MPN), an adaptive fractional integral terminal sliding mode power control (AFITSMPC) strategy has been proposed for the unified power flow controller (UPFC), which is compensating the MPN. The proposed AFITSMPC controls the $d q$ - axis series injected voltage, which controls the admittance model (AM) of the UPFC. As a result the power output of the DFIG stabilizes which helps in maintaining the equilibrium between the electrical and mechanical power of the nearby generators. Subsequently the rotor angular deviation of the respective generators gets recovered, which significantly stabilizes the MPN. The proposed AFITSMPC for the admittance model of the UPFC has been validated in a DFIG wind farm penetrated 2 area 4 machine power system in the MATLAB environment. The robustness and efficacy of the proposed control strategy of the UPFC, in contrast to the conventional PI control is vindicated under a number of intrinsic operating conditions, and the results analyzed are satisfactory.
\end{abstract}

Keywords: Adaptive fractional integral terminal sliding mode power control, Doubly fed induction generator, Multimachine power network, Unified power flow controller

\section{Introduction}

The increase in the penetration of wind power, especially from doubly fed induction generator based wind farms into the existing power grids, is although beneficial, but has significant pessimistic impacts [1] such as voltage and frequency control, power transfer capability, transient stability, etc. The employment of the power system stabilizers (PSS) is helpful in stabilizing such power systems, but they demonstrate an unreliable performance for the interarea oscillations between the generators of the multimachine power systems [2]. In the process, the application of the Flexible AC Transmission System (FACTS) devices, such as Unified Power Flow Controllers (UPFC) along with the PSS has illustrated excellent results, especially for improving the oscillations exhibited by the power system components [3]. Adding to it, they also control both the active

\footnotetext{
*Correspondence: pkdash.india@gmail.com

${ }^{1}$ Siksha O Anusandhan University, Khandagiri Square, Bhubaneswar, Odisha 751030, India

Full list of author information is available at the end of the article
}

and reactive power flows across the ac transmission lines $[4,5]$. A number of configurations of the UPFC used for the ac transmission lines in the last few decades have been reviewed in [6]. Most of the models constitute a large number of parameters involved and hence are computationally more complex. On the contrary, a simple model which is easier for deriving the controls has been proposed in [7], where the voltage injected in the series portion of the UPFC is resolved into quadrature and phase components, with respect to the current flowing along the line. These components are further used to effectively control the reactive and active power flow through the transmission line, respectively.

A review on some of the control systems for the UPFC as well as their drawbacks has been discussed in [8]. The proportional-integral (PI) control is one of the effective conventional controller for the UPFC [9], but its performance is unreliable under some of the intermittent operating conditions (DFIG based wind farms) [10]. In the due course of time some of the 
non-linear controls such as sliding mode control [10] (SMC), Neuro-SMC techniques [11] etc., have been proposed for the control of the UPFC. The choice of an ideal hyper plane that assures the asymptotic stability of the non- linear systems is very much important for the controller design of the SMC. Adding to it, SMC is endowed with the well-known chattering phenomenon which makes it unreliable under certain operating conditions. Thus in order to overcome the above mentioned problems, a fractional integral terminal sliding mode power control (FITSMPC) has been investigated for the nonlinear and dynamic systems [12] that shows a very much promising result in terms of guaranteed finite time chatter free error convergence.

In view of the discussions made above, the major contributions of the paper are listed as follows:

(a) A FITSMPC is proposed to control the dq- axis series injected voltage of the UPFC that subsequently controls the proposed admittance model of the UPFC.

(b) The controller gains of the proposed FITSMPC for the admittance model of the UPFC are made dynamic [13], such that they adjust with the intermittent operating conditions.

(c) This subsequently controls the active power injection at the DFIG wind farm terminal, which maintains the power balance of the nearby generators. As a result, the rotor angular oscillations between the generators in the multimachine system gets recovered, which will help in improving the power transfer capability of the associated transmission lines (though this later portion has not been investigated in the current paper, but is considered for future work).

The proposed controllers for the admittance model of the UPFC is installed in a standard 2-area 4-machine system [7], which has been penetrated by a DFIG based wind farm [14]. The overall model with their controllers have been simulated in the MATLAB/Editor environment following the necessary requirements for multimachine simulation [15]. The size and location for installation of the UPFC and DFIG based wind farm in the multimachine power system has been followed as per the references $[7,16]$, respectively. Critical Clearing Time $\left(T_{C C L}\right)[1]$, one of the key indicators of the transient stability index, has been taken as the basis for comparison of the performance of the proposed controller with the conventional PI control of the admittance model of the UPFC installed in the DFIG wind farm penetrated multimachine power system, and which is subjected to three phase fault and the DFIG wind farm experiences a realistic wind profile [17]. It is observed that as compared to the conventional PI control, the proposed control strategy for the admittance model of the UPFC is very much significant and robust in improving the transient stability of the DFIG penetrated multimachine power system and exhibits the largest $T_{C C L}$ for all most all the cases simulated in this paper. These outputs as illustrated in the simulation and results section are satisfactory and vindicate the real time application of the proposed technique.

\section{Proposed admittance model of UPFC}

\subsection{Basic model of the UPFC}

Figure 1 illustrates the single line diagram of an UPFC connected within the buses ' $m$ ' and ' $n$ ' (with bus voltage magnitudes $V_{m}\left\llcorner\delta_{m}\right.$ and $V_{n}\left\llcorner\delta_{n}\right.$, respectively). As a generalized concept of the UPFC [7], it comprises of a series transformer $\left(T_{s b t}\right)$, a shunt exciter transformer $\left(T_{\text {shet }}\right)$, a common dc link capacitor and two voltage source converters. In fact the bus ' $n$ ' is very nearer to bus ' $m$ ', as compared to bus ' $o$ ' (with bus voltage magnitude $V_{o}\left\llcorner\delta_{o}\right.$ ), as per the inequality relation " $\left(x_{S E}+x_{T s b t}\right)<<x_{T r}$. Line", where $x_{S E}$, $x_{T s b t}$ and $x_{T r}$. Line are the reactance's of the series portion of UPFC, transformer $T_{s b t}$ and the transmission line between bus ' $n$ ' and ' $o$, respectively.

Figure 2 shows the equivalent circuit of the UPFC in terms of controlled current sources, where $x_{S H}$ represents the reactance's across the shunt portions of the UPFC. $\xi_{S H}$ and $\xi_{S E}$ represent the susceptances of the shunt and series converter transformers of respectively. Similarly, $v$ and $v_{S H}$ represent the angle of the $V_{T s b t}$ the UPFC, and $V_{\text {Tshet }}$ with respect to $V_{m}$, respectively; $\delta_{m}$ and $\delta_{n}$ are the phase angle at buses ' $m$ ' and 'n', respectively.

Motivated from [7], let us assume $\mu_{\alpha}\left|V_{m}\right|$ and $\mu_{\beta}\left|V_{m}\right|$ be the induced voltage across $T_{s b t}$ and $T_{\text {shet }}$, respectively, where $\mu_{\alpha}$ and $\mu_{\beta}$ are the voltage proportion level of the series and shunt circuits of the UPFC, respectively. Thus expression for the injection of the active and reactive powers at buses ' $m$ ' and ' $n$ ' $\left(P_{m}, Q_{m}, P_{n}\right.$ and $\left.Q_{n}\right)$, respectively, can be defined as:

$$
\left.\begin{array}{l}
P_{m}=\mu_{\beta}\left|V_{m}\right|^{2} \xi_{S H} \sin \left(v_{S H}\right)+\mu_{\alpha}\left|V_{m}\right|^{2} \xi_{S E} \sin (v) \\
Q_{m}=\mu_{\beta}\left|V_{m}\right|^{2} \xi_{S H} \cos \left(v_{S H}\right)+\mu_{\alpha}\left|V_{m}\right|^{2} \xi_{S E} \cos (v)-\left|V_{m}\right|^{2} \xi_{S H} \\
P_{n}=-\mu_{\alpha}\left|V_{m}\right|\left|V_{n}\right| \xi_{S E} \sin \left(\delta_{b}+v\right) \\
Q_{n}=-\mu_{\alpha}\left|V_{m}\right|\left|V_{n}\right| \xi_{S E} \cos \left(\delta_{b}+v\right)
\end{array}\right\}
$$

It is further stated that, in order to attain a permissible operation of the shunt converters, $v_{S H} \approx 0$. Thus we derive: 


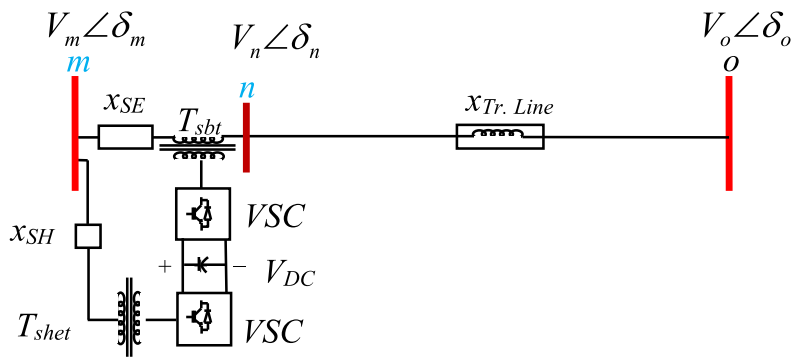

Fig. 1 The single line diagram of an UPFC

$$
\begin{aligned}
& \mu_{\beta}\left|V_{m}\right|^{2} \xi_{S H} \sin \left(v_{S H}\right) \approx 0 \text { and } \\
& \qquad \mu_{\beta}\left|V_{m}\right|^{2} \xi_{S H} \cos \left(v_{S H}\right)-\left|V_{m}\right|^{2} \xi_{S H} \approx 0
\end{aligned}
$$

Consequently, it can be rewritten as:

$$
\left.\begin{array}{l}
P_{m}=\mu_{\alpha}\left|V_{m}\right|^{2} \xi_{S E} \sin (v) \\
Q_{m}=\mu_{\alpha}\left|V_{m}\right|^{2} \xi_{S E} \cos (v)
\end{array}\right\}
$$

It is to be noted that the autonomous control mechanism of the shunt as well as the series converter of the UPFC rarely leads to an exact balance of power between them and hence some appropriate power injections must be added to attain so. In accordance to it, the active power at bus 'm' can be revisited as:

$$
P_{m}=\mu_{\alpha}\left|V_{m}\right|^{2} \xi_{S E} \sin (v)+\left|V_{m}\right|\left|I_{S H}\right|
$$

where $I_{S H}$ corresponds to the real component of the current across the shunt converter.

\subsection{Admittance model of the UPFC}

Thus UPFC can be treated as admittances $\left(Y_{m}\right.$ and $\left.Y_{n}\right)$ which can be expressed in terms of the active and reactive power across the two buses ' $m$ ' and ' $n$ ' $\left(P_{m}, Q_{m}, P_{n}\right.$ and $\left.Q_{n}\right)$, respectively, as shown in Fig. 3.

$Y_{m}$ and $Y_{n}$ can be expressed mathematically as:

$$
\left.\begin{array}{l}
Y_{m}=\left[P_{m}-j Q_{m}\right] /\left|V_{m}\right|^{2} \\
Y_{n}=\left[P_{n}-j Q_{n}\right] /\left|V_{n}\right|^{2}
\end{array}\right\}
$$

Substituting the expressions of $P_{m}, Q_{m}, P_{n}$ and $Q_{n}$ from Eqs. (4), and (1) in Eq. (5), we derive,

$$
\begin{aligned}
Y_{m} & =\mu_{\alpha}\left|V_{m}\right|^{2} \xi_{S E} \sin (v)+\left|V_{m}\right|\left|I_{S H}\right|-j\left[\mu_{\alpha}\left|V_{m}\right|^{2} \xi_{S E} \cos (v)\right] /\left|V_{m}\right|^{2} \\
& =\mu_{\alpha} \xi_{S E}[\sin (v)-j \cos (v)]+\left|V_{m}\right|^{-1}\left|I_{S H}\right|
\end{aligned}
$$

Similarly,

$$
\begin{aligned}
Y_{n} & =-\mu_{\alpha}\left|V_{m}\right|\left|V_{n}\right| \xi_{S E} \sin \left(\delta_{b}+v\right)-j\left(-\mu_{\alpha}\left|V_{m}\right|\left|V_{n}\right| \xi_{S E} \cos \left(\delta_{b}+v\right)\right) /\left|V_{n}\right|^{2} \\
& =-\mu_{\alpha} \xi_{S E}\left[\sin \left(\delta_{n}+v\right)-j \cos \left(\delta_{n}+v\right)\right]\left|V_{n}\right|^{-1}\left|V_{m}\right|
\end{aligned}
$$

\subsection{Design of $\mu_{a}$ and $v$}

Let us consider $\vartheta_{\zeta D}$ and $\vartheta_{\zeta \mathrm{Q}}$ are the direct and quadrature axis voltage injected in the series circuit of the UPFC $\left(\vartheta_{\zeta}\right)$, i.e.

$$
\vartheta_{\zeta}=\sqrt{\vartheta_{\zeta D}^{2}+\vartheta_{\zeta Q}^{2}}
$$

Now in order to attain a power flow control of the series inverter of the UPFC, $\vartheta_{\zeta}$ can be resolved $\left(\vartheta_{\zeta P}\right.$ and $\left.\vartheta_{\zeta \mathrm{Q}}\right)$ across the series current $I_{\zeta}$ such that:

$$
\left.\begin{array}{l}
\vartheta_{\zeta P}=\vartheta_{\zeta D} \sin \left(\delta_{\xi}\right)+\vartheta_{\zeta Q} \cos \left(\delta_{\xi}\right) \\
\vartheta_{\zeta R}=\vartheta_{\zeta Q} \sin \left(\delta_{\xi}\right)-\vartheta_{\zeta D} \cos \left(\delta_{\xi}\right)
\end{array}\right\}
$$

where

$$
\delta_{\xi}=\tan ^{-1}\left(i_{\zeta D} / i_{\zeta Q}\right)
$$

and

$$
i_{\zeta}=\sqrt{i_{\zeta D}^{2}+i_{\zeta Q}^{2}}
$$

Where $i_{\zeta D}$ and $i_{\zeta Q}$ re the dq- axis component of the series injected current $I_{\zeta}$.

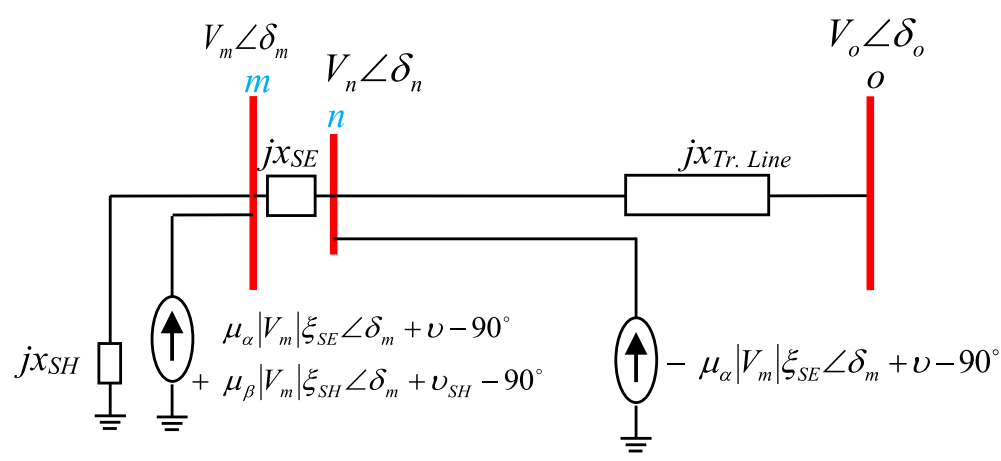

Fig. 2 Equivalent circuit of the UPFC in terms of controller current sources 


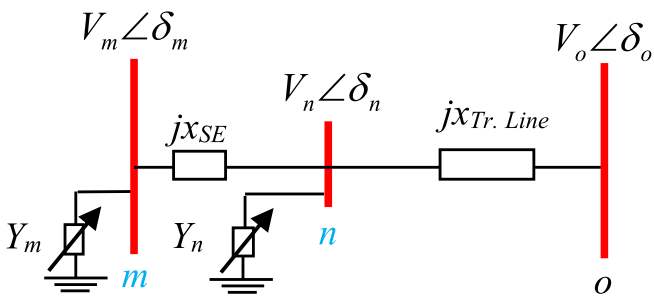

Fig. 3 Equivalent circuit of the proposed UPFC as controllable admittances

The relation between the bus voltage ' $V_{m}$ ' and the series injected voltage ' $\vartheta_{\zeta}$ ' can be expressed in dq axis as:

$$
\left.\begin{array}{l}
\vartheta_{\zeta D}=\mu_{\alpha} V_{m D} \cos (v)-\mu_{\alpha} V_{m Q} \sin (v) \\
\vartheta_{\zeta R}=\mu_{\alpha} V_{m D} \sin (v)+\mu_{\alpha} V_{m Q} \cos (v)
\end{array}\right\}
$$

Finally, the parameters $\mu_{\alpha}$ and $v$ are designed as:

$\mu_{\alpha}=\frac{\sqrt{\vartheta_{\zeta P}^{2} \vartheta_{\zeta Q}^{2}}}{V_{m}}$ and $v=\tan ^{-1}\left(\frac{i_{\zeta D}}{i_{\zeta Q}}\right)+\tan ^{-1}\left(\frac{V_{m D}}{V_{m Q}}\right)+\tan ^{-1}\left(\frac{\vartheta_{\zeta P}}{\vartheta_{\zeta Q}}\right)$

Thus UPFC has been modeled as controllable admittance loads as specified in Eqs. (6) and (7), respectively. It is to be noted that the admittance across the loads $Y_{m}$ and $Y_{n}$, can be controlled by $\mu_{\alpha}$ and $u$ which are again controlled by $\vartheta_{\zeta P}$ and $\vartheta_{\zeta Q}$, respectively, which depends upon $\delta_{\xi}, \vartheta_{\zeta D}$ and $\vartheta_{\zeta D}$, respectively. Thus the control of the UPFC as controllable loads is achieved by controlling the series injected voltage, as shown in Eq. (22), which is the main contribution of this manuscript. Modelling of the dc link voltage is referred to [7].

\section{Methods}

\subsection{The non- linear dynamic model of the UPFC}

The dynamic power model of the series SSSC of the UPFC in form of a state- space representation can be defined as

$$
\begin{aligned}
& \dot{p}_{n}=-\omega p_{n}+x_{S E}^{-1} \gamma_{Q} \\
& \dot{q}_{n}=\omega q_{n}+x_{S E}^{-1} \gamma_{P}
\end{aligned}
$$

$\gamma_{Q}$ and $\gamma_{P}$ are the control terms associated with the non-linear dynamic Eq. (17), which are defined as:

$$
\left.\begin{array}{l}
\gamma_{Q}=\left[\left(V_{m D}^{2}+V_{m Q}^{2}\right)-\left(V_{m Q} \vartheta_{x Q}-V_{m D} \vartheta_{x D}\right)\right] \\
\gamma_{P}=\left[\left(V_{m D} \vartheta_{x Q}-V_{m Q} \vartheta_{x D}\right)\right]
\end{array}\right\}
$$

In the above Eq. (15), the terms $\vartheta_{x D}$ and $\vartheta_{x Q}$ are defined as:

$$
\left.\begin{array}{l}
\vartheta_{x D}=\vartheta_{\zeta D}+V_{n D} \\
\vartheta_{x Q}=\vartheta_{\zeta Q}+V_{n Q}
\end{array}\right\}
$$

Rearranging Eq. (16), we have:

$$
\left.\begin{array}{l}
\vartheta_{x D}=V_{m Q} \gamma_{P}+V_{m D} \hat{\gamma}_{Q} /\left[V_{m D}^{2}-V_{m Q}^{2}\right] \\
\vartheta_{x Q}=V_{m D} \gamma_{P}+V_{m Q} \hat{\gamma}_{Q} /\left[V_{m D}^{2}-V_{m Q}^{2}\right]
\end{array}\right\}
$$

where

$$
\hat{\gamma}_{Q}=\left[\gamma_{Q}-V_{m D}^{2}-V_{m Q}^{2}\right]
$$

Finally the control objective is attained as:

$$
\left.\begin{array}{l}
\vartheta_{\zeta D}=\vartheta_{x D}-V_{n D} \\
\vartheta_{\zeta Q}=\vartheta_{x Q}-V_{n Q}
\end{array}\right\}
$$

Thus $\gamma_{Q}$ and $\gamma_{P}$ are the target control terms which are used to control the final dq- axis series injected voltages (Eq. (34)), which subsequently control the proposed AM of the UPFC, respectively.

\subsection{Proposed adaptive fractional integral terminal sliding mode power control (AFITSMPC) of UPFC}

Reformulating the dynamic power model of the series SSSC of the UPFC (Eq. (17)):

$$
\dot{x}=A x+B u
$$

where

$$
\begin{aligned}
A & =\left[\begin{array}{cc}
-\omega & 0 \\
0 & \omega
\end{array}\right], B=\left[\begin{array}{cc}
x_{S E}^{-1} & 0 \\
0 & x_{S E}^{-1}
\end{array}\right], x=\left[\begin{array}{l}
X_{1} \\
X_{2}
\end{array}\right] \\
& =\left[\begin{array}{l}
p_{n} \\
q_{n}
\end{array}\right], \text { and } u=\left[\begin{array}{c}
\gamma_{Q} \\
\gamma_{P}
\end{array}\right]
\end{aligned}
$$

The tracking error functions for the controller, in terms of the active and reactive power of the SSSC of the UPFC are defined as:

$$
\left[\begin{array}{l}
e_{r 1} \\
e_{r 2}
\end{array}\right]=\left[\begin{array}{c}
p_{n}^{*} \\
q_{n}^{*}
\end{array}\right]-\left[\begin{array}{l}
p_{n} \\
q_{n}
\end{array}\right]
$$

Where $p_{n}^{*}$ and $q_{n}^{*}$ are the reference value of the active and reactive powers, which are evaluated in the initial solution.

Taking the derivative of Eq. (22) with respect to time on both sides, we derive:

$$
\left[\begin{array}{c}
\dot{e}_{r 1} \\
\dot{e}_{r 2}
\end{array}\right]=\left[\begin{array}{cc}
\omega & 0 \\
0 & -\omega
\end{array}\right]\left[\begin{array}{l}
p_{n} \\
q_{n}
\end{array}\right]-\left[\begin{array}{cc}
0 & x_{S E}^{-1} \\
x_{S E}^{-1} & 0
\end{array}\right]\left[\begin{array}{l}
\gamma_{P} \\
\gamma_{Q}
\end{array}\right]
$$

The fractional Integral terminal sliding surface (FITSS) are defined as: 


$$
\left[\begin{array}{c}
\sigma_{r 1} \\
\sigma_{r 2}
\end{array}\right]=\left[\begin{array}{l}
e_{r 1} \\
e_{r 2}
\end{array}\right]+\left[\begin{array}{cc}
\alpha_{1} & 0 \\
0 & \alpha_{2}
\end{array}\right]\left[\begin{array}{l}
e_{I r 1} \\
e_{I I r 2}
\end{array}\right]
$$

where

$$
\left[\begin{array}{l}
\dot{e}_{I r 1} \\
\dot{e}_{I I r 2}
\end{array}\right]=\left[\begin{array}{ll}
1 & 0 \\
0 & 1
\end{array}\right]\left[\begin{array}{l}
e_{r 1}^{\beta_{1}} \\
e_{r 2}^{\beta_{2}}
\end{array}\right]
$$

With $\alpha_{1}, \alpha_{2}>0, \beta_{1}, \beta_{2}$ are fractional numbers satisfying the relation $0<\left[\beta_{1}, \beta_{2}\right]<1$.

Integrating the above Eq. (25), and replacing the resultant in Eq. (23), the final expression for the FITSS in terms of the tracking error is defined as,

$$
\left[\begin{array}{l}
\sigma_{r 1} \\
\sigma_{r 2}
\end{array}\right]=\left[\begin{array}{l}
e_{r 1} \\
e_{r 2}
\end{array}\right]+\left[\begin{array}{cc}
\alpha_{1} & 0 \\
0 & \alpha_{2}
\end{array}\right]\left[\begin{array}{c}
\int e_{r 1}^{\beta_{1}} \\
\int e_{r 2}^{\beta_{2}}
\end{array}\right]
$$

where $\left(\beta_{1}, \beta_{2}\right)$ are the fractional powers of the tracking errors $\left(e_{r 1}, e_{r 2}\right)$ with initial values $\left(-e_{r 1}(0) / \alpha_{1},-e_{r 1}(0) / \alpha_{1}\right)$, respectively.

The derivative of the above Eq. (26) is defined as:

$$
\left[\begin{array}{c}
\dot{\sigma}_{r 1} \\
\dot{\sigma}_{r 2}
\end{array}\right]=\left[\begin{array}{c}
\dot{e}_{r 1} \\
\dot{e}_{r 2}
\end{array}\right]+\left[\begin{array}{cc}
\alpha_{1} & 0 \\
0 & \alpha_{2}
\end{array}\right]\left[\begin{array}{c}
e_{r 1}^{\beta_{1}} \\
e_{r 2}^{\beta_{2}}
\end{array}\right]
$$

Replacing Eq. (23) in Eq. (27), we derive:

$$
\begin{aligned}
\Rightarrow\left[\begin{array}{c}
\dot{\sigma}_{r 1} \\
\dot{\sigma}_{r 2}
\end{array}\right] & =\left[\begin{array}{cc}
\omega & 0 \\
0 & -\omega
\end{array}\right]\left[\begin{array}{l}
p_{n} \\
q_{n}
\end{array}\right]+\left[\begin{array}{cc}
\alpha_{1} & 0 \\
0 & \alpha_{2}
\end{array}\right]\left[\begin{array}{c}
e_{r 1}^{\beta_{1}} \\
e_{r 2}^{\beta_{2}}
\end{array}\right] \\
& -\left[\begin{array}{cc}
0 & x_{S E}^{-1} \\
x_{S E}^{-1} & 0
\end{array}\right]\left[\begin{array}{l}
\gamma_{P} \\
\gamma_{Q}
\end{array}\right]
\end{aligned}
$$

Theorem 1 The tracking error functions as defined in Eq. (25) will converge to zero in a finite amount of time, and the system will remain robust and stable if the FITSS are chosen as in Eq. (32), and the control is designed as follows:

$$
\left[\begin{array}{l}
\gamma_{P} \\
\gamma_{Q}
\end{array}\right]=\left[\begin{array}{l}
\gamma_{\text {Pnom }} \\
\gamma_{\text {Qnom }}
\end{array}\right]+\left[\begin{array}{l}
\gamma_{\text {Prob }} \\
\gamma_{\text {Qrob }}
\end{array}\right]
$$

where $\gamma_{\text {Pnom }}$ and $\gamma_{\text {Qnom }}$ are the nominal controls, whereas $\gamma_{\text {Prob }}$ and $\gamma_{Q \text { rob }}$ are the robust controls, respectively, as introduced by the terminal sliding mode concept and can be derived as follows:

$$
\begin{aligned}
{\left[\begin{array}{l}
\gamma_{\text {Pnom }} \\
\gamma_{\text {Qnom }}
\end{array}\right] } & =\left[\begin{array}{cc}
0 & -\omega x_{S E} \\
\omega x_{S E} & 0
\end{array}\right]\left[\begin{array}{l}
p_{n} \\
q_{n}
\end{array}\right] \\
& +\left[\begin{array}{cc}
0 & \alpha_{2} x_{S E} \\
\alpha_{1} x_{S E} & 0
\end{array}\right]\left[\begin{array}{l}
e_{r 1}^{\beta_{1}} \\
e_{r 2}^{\beta_{2}}
\end{array}\right]
\end{aligned}
$$

$$
\left[\begin{array}{l}
\dot{\gamma}_{\text {Prob }} \\
\dot{\gamma}_{\text {Qrob }}
\end{array}\right]=\left[\begin{array}{l}
\gamma_{\text {ProbV }} \\
\gamma_{\text {QrobV }}
\end{array}\right]-\left[\begin{array}{cc}
\beta_{\text {Prob }} & 0 \\
0 & \beta_{\text {Qrob }}
\end{array}\right]\left[\begin{array}{l}
\gamma_{\text {Prob }} \\
\gamma_{\text {Qrob }}
\end{array}\right]
$$

where

$$
\begin{aligned}
& {\left[\begin{array}{l}
\gamma_{\text {ProbV }} \\
\gamma_{\text {QrobV }}
\end{array}\right]=\left[\begin{array}{cc}
\hat{\beta}_{\text {ProbV }} & 0 \\
0 & \hat{\beta}_{\text {QrobV }}
\end{array}\right]\left[\begin{array}{l}
\operatorname{sign}\left(\sigma_{r 2}\right) \\
\operatorname{sign}\left(\sigma_{r 1}\right)
\end{array}\right]} \\
& {\left[\begin{array}{l}
\dot{\hat{\beta}}_{\text {ProbV }} \\
\dot{\hat{\beta}}_{\text {QrobV }}
\end{array}\right]=-\left[\begin{array}{cc}
\beta_{\text {ProbA }} & 0 \\
0 & \beta_{\text {QrobA }}
\end{array}\right]\left[\begin{array}{l}
\left|\sigma_{r 2}\right| \\
\left|\sigma_{r 1}\right|
\end{array}\right]}
\end{aligned}
$$

In the above Eqs. (34)-(37), $\left\{\beta_{\text {Probv }} \beta_{\text {QrobV }} \beta_{\text {ProbA }}\right.$, $\left.\beta_{\text {QrobA }}\right\}>0$, are the gains of the controller, whose initial values are mentioned in the Appendix. Eq. (37), which makes the controller adaptive i.e., adjusts the controller gains according to the varying operating conditions, is defined as the fractional integral terminal sliding mode adaptive law for the admittance model of the UPFC.

Proof of convergence On the surface $\dot{\sigma}_{r 1}=0$ and $\dot{\sigma}_{r 2}=0$ we have,

$$
\left[\begin{array}{c}
\dot{e}_{r 1} \\
\dot{e}_{r 1}
\end{array}\right]=-\left[\begin{array}{c}
\alpha_{1} e_{r 1}^{\beta_{1}} \\
\alpha_{2} e_{r 2}^{\beta_{2}}
\end{array}\right] \Rightarrow\left[\begin{array}{c}
\dot{e}_{r 1} \\
\alpha_{1} e_{r 1}^{\beta_{1}} \\
\dot{e}_{r 2} \\
\hline \alpha_{2} e_{r 2}^{\beta_{2}}
\end{array}\right]=-\left[\begin{array}{l}
1 \\
1
\end{array}\right]
$$

Integrating the above Eq. (39), and then rearranging the resultant term, the convergence time of the tracking errors are derived as:

$$
\left[\begin{array}{c}
t_{r 1} \\
t_{r 2}
\end{array}\right]=\left[\begin{array}{c}
\frac{\left|e_{I r 1}\right|^{1-\beta_{1}}}{\alpha_{1}^{\beta_{1}}\left(1-\beta_{1}\right)} \\
\frac{\left|e_{I r 2}\right|^{1-\beta_{2}}}{\alpha_{2}^{\beta_{2}}\left(1-\beta_{2}\right)}
\end{array}\right]=\left[\begin{array}{c}
\frac{\left|e_{r 1}\right|^{1-\beta_{1}}}{\alpha_{1}\left(1-\beta_{1}\right)} \\
\frac{\left|e_{r 2}\right|^{1-\beta_{2}}}{\alpha_{2}\left(1-\beta_{2}\right)}
\end{array}\right]
$$

Equation (39) guarantees a finite time convergence of the tracking error functions [12] as defined in Eq. (25).

Proof of stability Let us consider the following Lyapunov function:

$$
\begin{aligned}
V_{L} & =\frac{1}{2} \sigma_{r 1}^{2}+\frac{1}{2} \sigma_{r 2}^{2}+\frac{1}{\beta_{\text {ProbA }}}\left(\dot{\hat{\beta}}_{\operatorname{Pr} o b V}-\hat{\beta}_{\operatorname{Pr} o b V}\right)^{2} \\
& +\frac{1}{\beta_{\text {QrobA }}}\left(\dot{\hat{\beta}}_{\text {QrobV }}-\hat{\beta}_{\text {QrobV }}\right)^{2}
\end{aligned}
$$

Taking the derivative of the above Eq. (40) w.r.t time on both sides, we derive: 


$$
\begin{aligned}
\dot{V}_{L} & =\sigma_{r 1} \dot{\sigma}_{r 1}+\sigma_{r 2} \dot{\sigma}_{r 2}+\left(\dot{\hat{\beta}}_{\operatorname{ProbV}}-\hat{\beta}_{\operatorname{ProbV}}\right)\left|\sigma_{r 2}\right| \\
& +\left(\dot{\hat{\beta}}_{\mathrm{QrobV} V}-\hat{\beta}_{\mathrm{QrobV} V}\right)\left|\sigma_{r 1}\right|
\end{aligned}
$$

Substituting Eqs. (34)-(37) in eq. (32), we simplify as:

$$
\left[\begin{array}{c}
\dot{\sigma}_{r 1} \\
\dot{\sigma}_{r 2}
\end{array}\right]=-x_{S E}^{-1}\left[\begin{array}{l}
\left\{(1-h) \beta_{\text {Qrob }}\right\}+\left\{h \hat{\beta}_{\text {QrobV }} \operatorname{sign}\left(\sigma_{r 1}\right)\right\} \\
\left\{(1-h) \beta_{\text {Prob }}\right\}+\left\{h \hat{\beta}_{\text {ProbV }} \operatorname{sign}\left(\sigma_{r 2}\right)\right\}
\end{array}\right]
$$

where $\mathrm{h}$ is the step length equal to 0.01 .

Now substituting Eq. (42) in Eq. (41), we derive:

$$
\begin{aligned}
\dot{V}_{L}= & -\left[\left(1+h x_{S E}^{-1}\right) \hat{\beta}_{Q r o b V}-\dot{\hat{\beta}}_{Q r o b V}\right]\left|\sigma_{r 1}\right| \\
& -\left[\left(1+h x_{S E}^{-1}\right) \hat{\beta}_{\text {ProbV }}-\dot{\hat{\beta}}_{\text {ProbV }}\right]\left|\sigma_{r 2}\right| \\
& -x_{S E}^{-1}\left[\left(\sigma_{r 1}(1-h) \beta_{Q r o b}\right)+\left(\sigma_{r 2}(1-h) \beta_{\text {Prob }}\right)\right] \\
& \Rightarrow \quad \dot{V}_{L} \leq 0 \quad \text { for all } \sigma_{r 1} \neq 0 \text { and } \sigma_{r 2} \neq 0 .
\end{aligned}
$$

From Eq. (43), it is proved that as the value of $\dot{V}_{L} \leq 0$ for all $\sigma_{r 1} \neq 0$ and $\sigma_{r 2} \neq 0$, which guarantees the system stability. This completes the proof.

\section{DFIG wind farm model}

Motivated from [1], the large off-shore [18] 100 MW DFIGWF comprising 20 wind turbines rated at $5 \mathrm{MW}$ each is characterized by an equivalent amassed DFIG configuration, which is driven by an equivalent amassed DFIG wind turbine (DFIGWT), via a matching gearbox mechanism, as shown in Fig. 4. Thus each of the wind turbines present in the wind farm model is assumed to be identical, and the resulting wind farm is an aggregated version of a number of wind turbines. The parameters of a single DFIGWT are referred to [14]. As depicted from this figure, the DFIG stator terminals are directly connected to the low voltage side of the utility transformer (LVSUT), whereas, the DFIG rotor terminals are connected to the same LVSUT via a back to back, voltage source converter (VSC) based power electronic circuit.

The synchronous $d q$ reference frame based dynamic model of the DFIG wind turbine is developed from its flux linkage model [16], and is represented as:

$$
\begin{aligned}
\dot{\omega}_{r r}= & 0.5 \times\left(t_{s s h}-t_{e e}\right) / H_{g g} \\
\theta_{t w}= & \omega_{e e}\left(\omega_{t t}-\omega_{r r}\right) \\
\omega_{t t}= & 0.5 \times\left(t_{m m}-t_{s h}\right) / H_{t t} \\
E_{s d}= & -\frac{E_{s d}}{T_{r r}}+\left(\omega_{s s}-\omega_{r r}\right) E_{s q}+\omega_{s s} \frac{\left(L_{s s}-L_{s s}^{\prime}\right)}{T_{r r}} I_{s q} \\
& -\omega_{s s} K_{m r r} V_{r q}=\gamma_{1}-\gamma_{3} V_{r q} \\
E_{s q}= & -\frac{E_{s q}}{T_{r r}}-\left(\omega_{s s}-\omega_{r r}\right) E_{s d}-\omega_{s s} \frac{\left(L_{s s}-L_{s s}^{\prime}\right)}{T_{r r}} I_{s d} \\
& +\omega_{s s} K_{m r r} V_{r d}=\gamma_{2}+\gamma_{3} V_{r d} \\
V_{d c}= & \frac{P_{r r}-P_{i i}}{C_{d c} V_{d c}}=\frac{-\left(\omega_{s s}-\omega_{r r}\right) P_{s s}-P_{i i}}{C_{d c} V_{d c}}
\end{aligned}
$$

where $\omega_{r n} \omega_{t t}$ and $\omega_{s s}$ are the rotor, turbine and synchronous speeds of the DFIG, respectively. $E_{s d}$ and $E_{s q}$ denotes the voltage behind the transient reactance of the DFIG. $\theta_{\mathrm{tw}}$ represents the shaft twist angle. $C_{d c}$ and $V_{d c}$ are the capacitance and voltage components across the dc terminal of the DFIG, respectively. The constants $H_{g g}$ $H_{t t}$ are represents the inertia constants of generator and turbine, respectively. Similarly, $L_{s s}, L_{s s}^{\prime}, T_{r r}$ represent the synchronous inductance, transient inductance and time constant of DFIG respectively. Mathematically, $L_{s s}^{\prime}=\omega_{s s}$ $\left[L_{m m}^{2} / L_{r r}\right]$ and $T_{r r}=L_{r r} / r_{r n}$ where $L_{r r}$ and $r_{r r}$ are the rotor self-inductance and resistance, respectively, and $L_{m m}$ is the mutual inductance between the stator and the rotor terminals of the DFIG. $t_{m m}, t_{s h}$ and $t_{e e}$ are the mechanical, shaft and electromechanical torque of the DFIG respectively.

The total real and reactive power supplied by DFIG to the network is simplified as:

$$
\begin{aligned}
& P_{d f}=P_{s s}+P_{i i}=V_{s d} I_{s d}+V_{s q} I_{s q}+V_{r d} I_{r d}+V_{r q} I_{r q} \\
& Q_{d f}=Q_{s s}+Q_{i i}=V_{s q} I_{s d}-V_{s d} I_{s q}
\end{aligned}
$$

where $I_{r d}, I_{r q}, I_{s d}, I_{s q}, I_{i d}, I_{i q}, V_{r d}, V_{r q}, V_{s d}, V_{s q}, V_{i d}$, and $V_{i q}$, are the dq-axis current and voltage quantities of the RSC, stator, and GSC Terminals, respectively. Similarly, $P_{r n}, P_{s s}, P_{i i}, P_{d f}, Q_{r n} Q_{s s}, Q_{i i}$, and $Q_{d f}$ are the active and reactive power flows across the RSC, stator, GSC and DFIG terminals respectively.

The GSC operation has been restricted to unity power factor and hence, results in zero reactive power at the GSC terminal.

\section{Results}

Figure 5 illustrates the single line diagram of the test system i.e., the multimachine power system ( 2 area 4 machine system [19]), with a 100 MW DFIG based wind farm [14] (comprising a lumped model of 20 number of identical 5 MW DFIG based wind turbines) installed at 


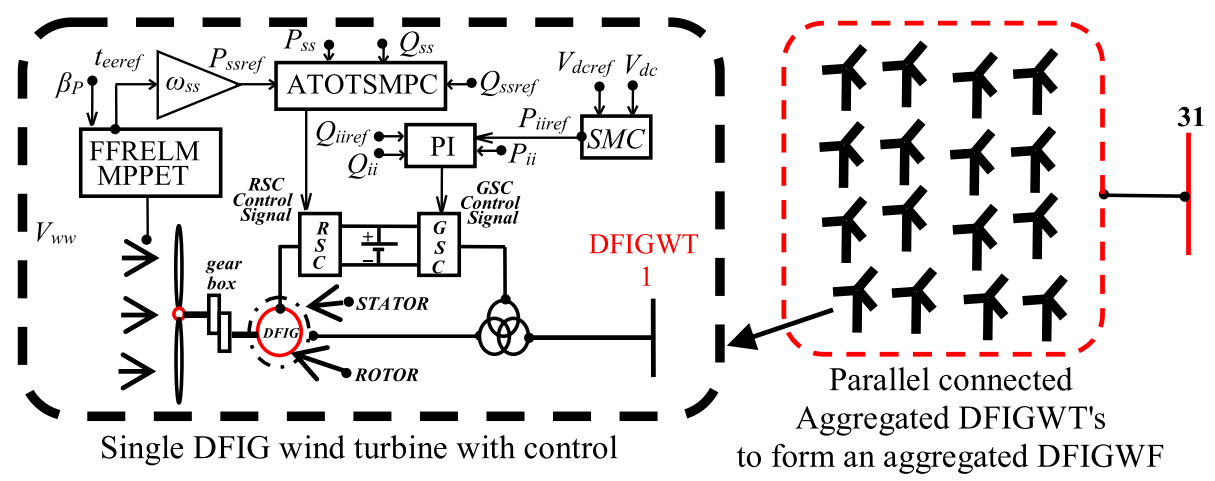

Fig. 4 Single line diagram of the aggregated DFIG based Wind Farm

the bus ' 7 ' and the 20 MVA equivalent admittance model of the UPFC [7] installed within the bus ' $m$ ' and ' $n$ ', respectively, (as has been explained in section II), and this model has been simulated in the MATLAB/Editor environment following the requirements for the multimachine simulations [15]. The generators in the multimachine system are enabled with PSS, and the details regarding the concepts, modeling, parameterization and dynamics of the various network components (including generators, transmission lines, transformers, PSS, DFIG based wind farm, UPFC, etc.) can be found in the literatures [14, 16, 19]. For simulating the power system shown in Fig. 4, the base MVA is chosen as 100. Further it is noted that the computational complexity associated with the dynamics of the network components, i.e., transformers, exciters, transmission lines, converters, etc., is very much high for MPN simulation, and hence following the IEEE 1547 norms and [15], they have been neglected in this paper. A sporadic wind profile [17], as shown in Fig. 5 is varying between $0.11 \mathrm{~m} / \mathrm{s}$ and $18.11 \mathrm{~m} / \mathrm{s}$, which matches to $(0-80) \%$ of total power generation capacity (TPGC) and (0-25.31) \% of total power penetration capacity (TPPC) of the DFIG wind farm, respectively [1].

As depicted in Fig. 6, number of operating conditions that have been selected are 'A (1.47 s, $8.38 \mathrm{~m} / \mathrm{s})$ ', 'B $(0.75 \mathrm{~s}, 7.30 \mathrm{~m} / \mathrm{s})$ ' and 'C (2.5 s, $16.59 \mathrm{~m} / \mathrm{s})$ ', and 'D $(3.05 \mathrm{~s}, 12.52 \mathrm{~m} / \mathrm{s})$ ' which corresponds to lower and higher wind speeds at positive and negative slopes, respectively. The penetration level of the DFIG wind power have been varied from (16.01-23.90) \% of the TPPC [1], which corresponds to $(0.51-0.76)$ p.u. of DFIG wind power penetration, and are denoted as the lower and higher penetration levels of the DFIG wind power, respectively. It is to be noted that, a PI control strategy is incorporated to the control the DFIG wind farm [13] converters. Figs. 6, 7, 8, 9, 10 and 11 illustrate the comparison of the cases where the STRATEGY A (red line) involves the conventional PI control of the AM of the UPFC, whereas the STRATEGY B (black line) involves the proposed AFITSMPC for the AM of the UPFC. The gains of the PI controllers for the DFIG as well as AM of UPFC are tuned through ITAE criterion

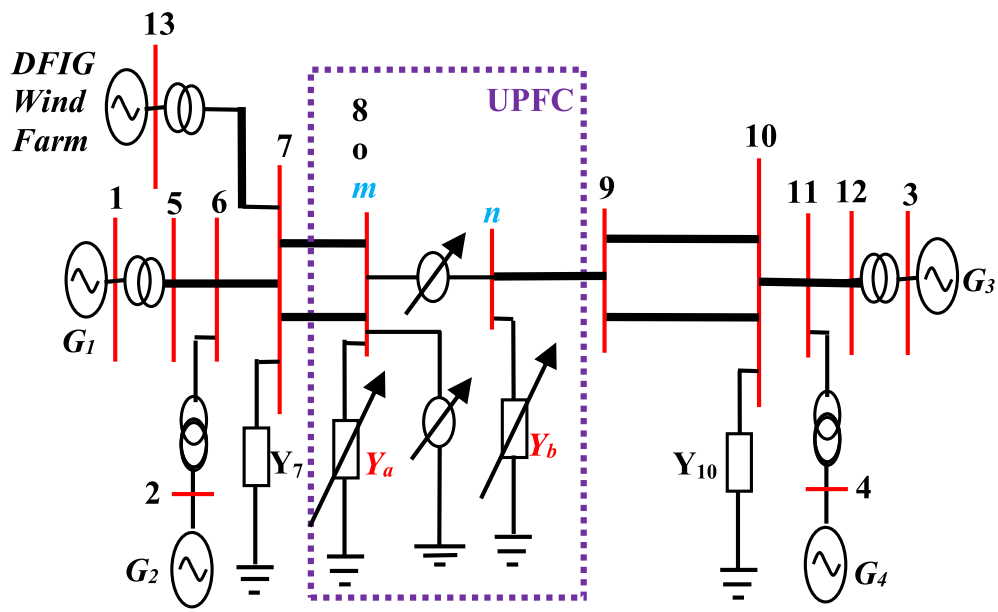

Fig. 5 Single line diagram of the test system 


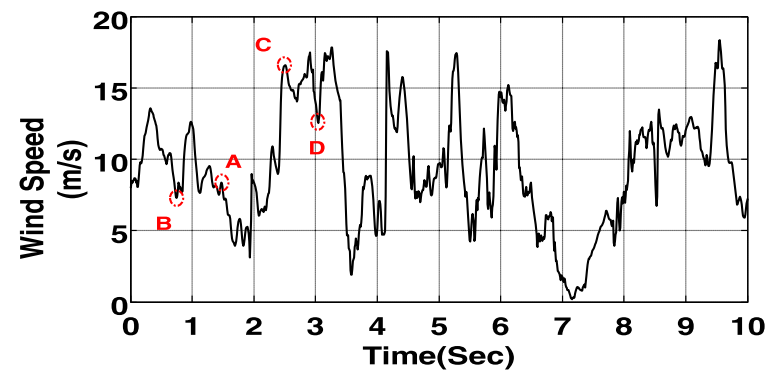

Fig. 6 The sporadic wind profile

[20], with possible maximum wind power penetration. The detailed values of the tuned gains for the PI controller for the DFIG as well as AM of UPFC are mentioned in the Appendix.

A three phase short-circuit fault is considered as the disturbance which has been simulated on one of the load bus (bus ' 7 ' in Fig. 5) for certain duration of time ' $t_{f}$ ' in sec. The highest value of $t_{f}$ in the post fault region within which synchronism between the relative rotor angles of the generators in a power system is maintained is defined as the critical clearing time denoted as $T_{C C L}$ [1]. Thus it is very much significant that, for a given operating condition, the $T_{C C L}$ provides an exact clue of the transient stability margin of the power system.
5.1 Performance of the control strategies of the UPFC in the DFIG wind farm penetrated two area four machine system (Fig. 5) with the DFIG wind farm subjected to fixed wind speed

In this particular case, a three phase fault is initiated on bus 7 of the test system (Fig. 5) at the timing instant $t_{s}=2.11 \mathrm{~s}$, where the DFIG wind farm is subjected to fixed wind speed of $6.29 \mathrm{~m} / \mathrm{s}$. The performance of the controllers has been tested for both the lower as well as higher level of penetration of the DFIG wind farm, which are illustrated in Figs. 7 and 8 , respectively. In order to evaluate the $T_{C C L}$, the performance of the proposed as well as conventional controls of the AM of the UPFC is observed by repetitive simulations by increasing the duration of fault ' $t_{f}$ '. It is observed that, the $T_{C C L}$ for the conventional PI control for this particular case is $249 \mathrm{~ms}$ and $161 \mathrm{~ms}$ for lower and higher penetration of DFIG wind farm, respectively, at which the generators in the system losses synchronism (subplots (d)). On the contrary, for the same duration of fault $\left(T_{C C L}\right.$ for PI control), the proposed control of the AM of the UPFC is very much significant in improving the ' $Y_{m}$ ' and ' $Y_{n}$ ' placed between the buses ' $\mathrm{m}$ ' and ' $\mathrm{n}$ ' as shown in subfigures (a) and (b), respectively. Subsequently, the power at the DFIG wind farm terminal $\left(P_{d g}\right)$ is improved (subplot (c)), which is responsible for restraining the electrical and mechanical power

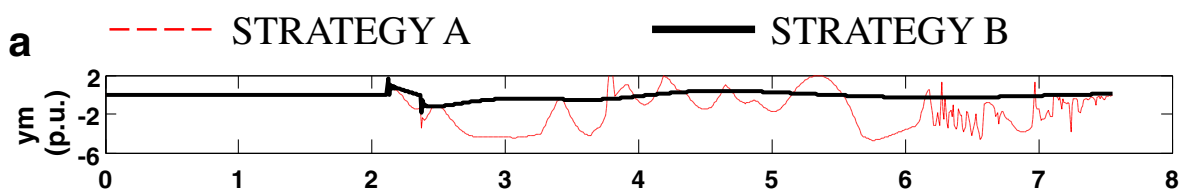

b

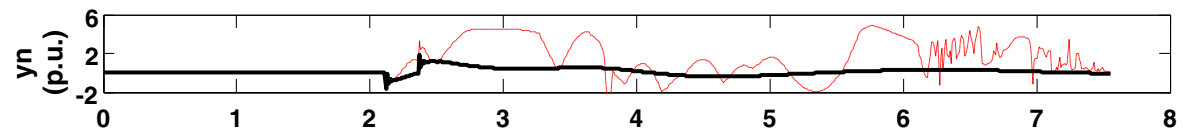

C

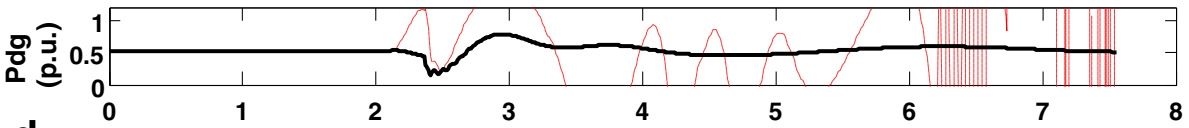

d

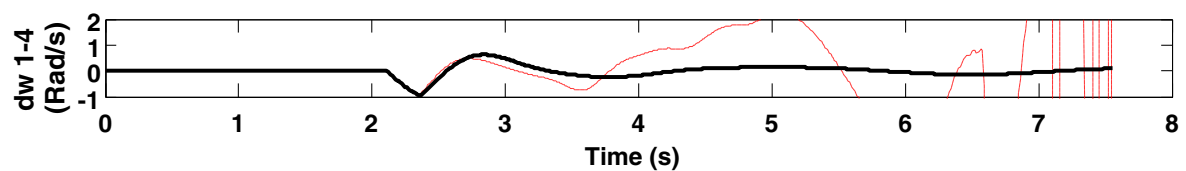

Fig. 7 The response of the proposed and conventional controls of the admittance model of the UPFC for a three phase to ground fault at time $t=2.11 \mathrm{~s}$ on the bus 7 of the test system as shown in Fig. 5, with a lower penetration of the DFIG wind farm which is subjected to a fixed speed of $6.29 \mathrm{~m} / \mathrm{s}$, where, a the admittance of the UPFC at bus ' $\mathrm{m}$ ' in p.u., $\mathbf{b}$ the admittance of the UPFC at bus ' $n$ 'in p.u., $\mathbf{c}$ the active power injection of the DFIG (p.u.), and $\mathbf{d}$ the interarea oscillation between the generators ' 1 ' and ' 4 ' in $\mathrm{Rad} / \mathrm{s}$, respectively 


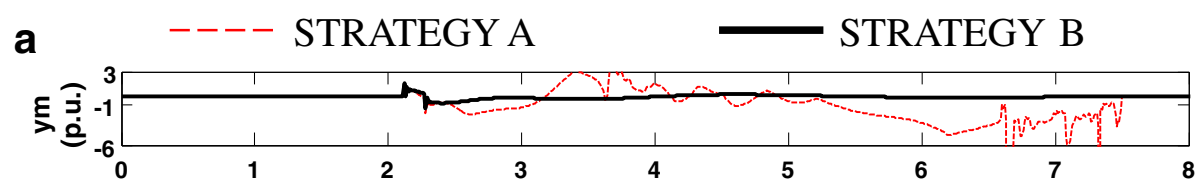

b

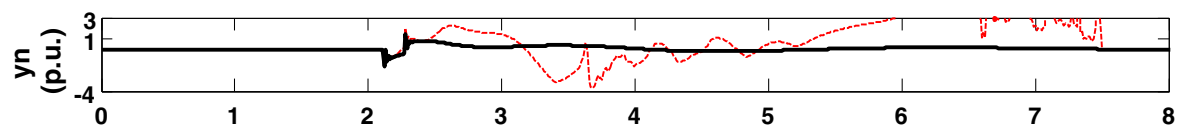

C

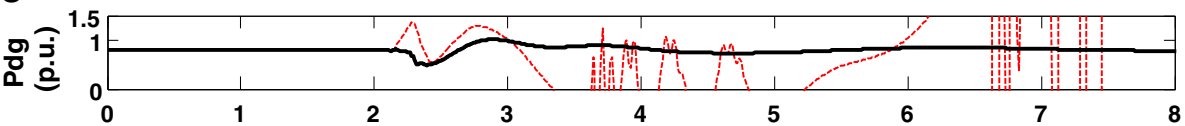

d

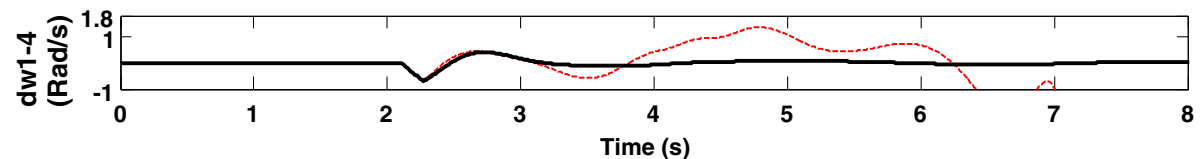

Fig. 8 The response of the proposed and conventional controls of the admittance model of the UPFC for a three phase to ground fault at time $t=2.11 \mathrm{~s}$ on the bus 7 of the test system as shown in Fig. 5, with a higher penetration of the DFIG wind farm which is subjected to a fixed speed of $6.29 \mathrm{~m} / \mathrm{s}$, where, a the admittance of the UPFC at bus ' $\mathrm{m}$ ' in p.u., $\mathbf{b}$ the admittance of the UPFC at bus ' $n$ 'in p.u., c the active power injection of the DFIG (p.u.), and $\mathbf{d}$ the interarea oscillation between the generators ' 1 ' and ' 4 ' in $\mathrm{Rad} / \mathrm{s}$, respectively

equilibrium of the nearby generators. This minimizes the rotor angular deviation of the generators and hence stabilizes the MPN, which is reflected in the improvement on the interarea oscillation between generators 1 and 4, (DW 1-4 ( $\mathrm{Rad} / \mathrm{s})$ ) as illustrated in subplot (d), in these figures, respectively. Further, the $T_{C C L}$ for the proposed control strategies is found out to be $266 \mathrm{~ms}$ and $181 \mathrm{~ms}$, for lower and higher penetration of DFIG wind farm, which illustrates a $17 \mathrm{~ms}$ and $20 \mathrm{~ms}$ improvement in CCL, respectively, for the proposed controller (STRATEGY B) in the fixed wind speed operation of the DFIG wind farm.
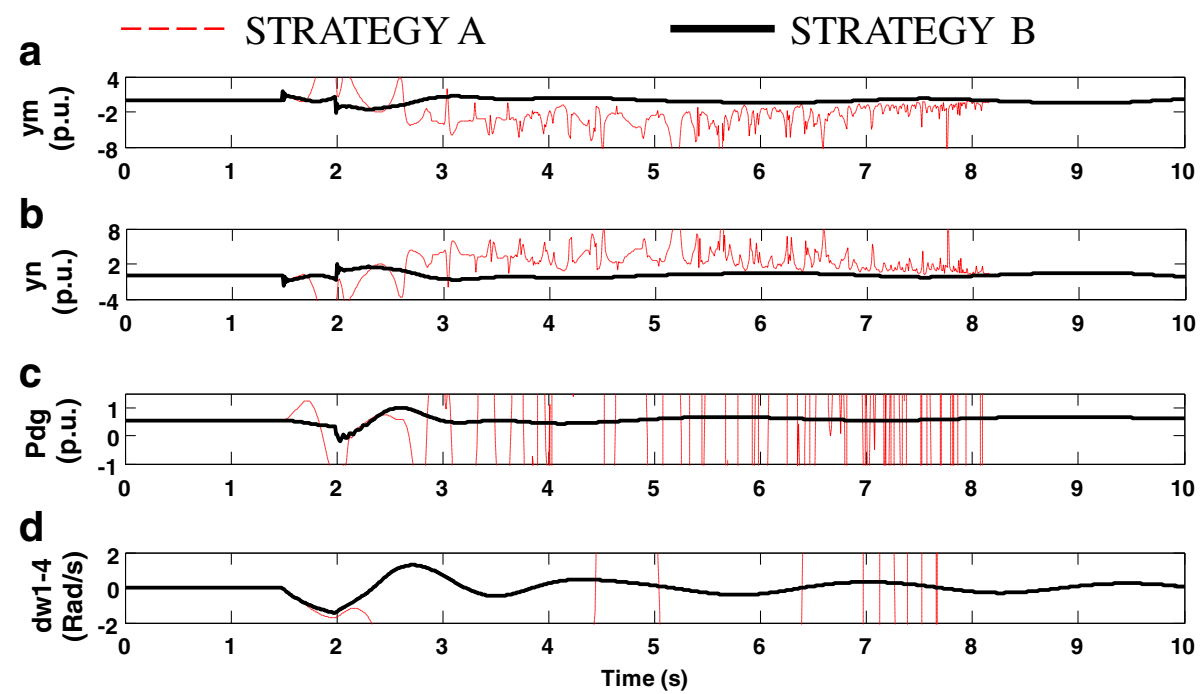

Fig. 9 The response of the proposed and conventional controls of the admittance model of the UPFC for a three phase to ground fault at time $t=1.47 \mathrm{~s}$ (operating point ' $A$ ') on the bus 7 of the test system as shown in Fig. 5, with a lower penetration of the DFIG wind farm which is subjected to a variable wind speed (Fig. 6), where, a the admittance of the UPFC at bus ' $m$ ' in p.u., $\mathbf{b}$ the admittance of the UPFC at bus ' $n$ 'in p.u., c the active power injection of the DFIG (p.u.), and $\mathbf{d}$ the interarea oscillation between the generators ' 1 ' and ' 4 ' in Rad/s, respectively 


\section{---- STRATEGY A}

\section{STRATEGY B}

a

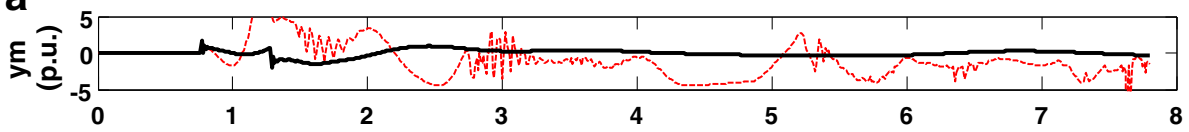

b

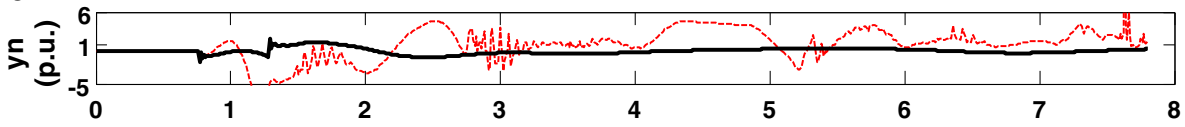

C

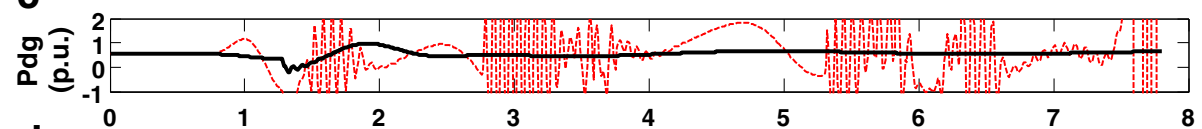

d

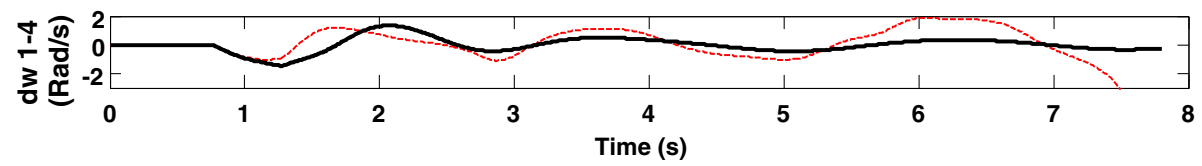

Fig. 10 The response of the proposed and conventional controls of the admittance model of the UPFC for a three phase to ground fault at time $t=0.75 \mathrm{~s}$ (operating point ' $\mathrm{B}$ ') on the bus 7 of the test system as shown in Fig. 5, with a lower penetration of the DFIG wind farm which is subjected to a variable wind speed (Fig. 6), where, a the admittance of the UPFC at bus ' $m$ ' in p.u., $\mathbf{b}$ the admittance of the UPFC at bus ' $n$ 'in p.u., c the active power injection of the DFIG (p.u.), and $\mathbf{d}$ the interarea oscillation between the generators ' 1 ' and ' 4 ' in $\mathrm{Rad} / \mathrm{s}$, respectively

5.2 Performance of the control strategies of the UPFC in the DFIG wind farm penetrated two area four machine system (Fig. 5) with the DFIG wind farm subjected to variable wind speed

In this particular case, the robustness in performance of the proposed AFITSMPC for the AM of the UPFC is verified for the stability enhancement of the MPN (Fig. 5) under both the lower as well as higher level of penetrations of the DFIG wind farm, for a three phase fault initiated on bus 7 at the timing instants ' $A$ ', 'B' ' $C$ ' and 'D', respectively, with a sporadic wind profile input to the DFIG wind farm and the results are illustrated in Figs. 9,

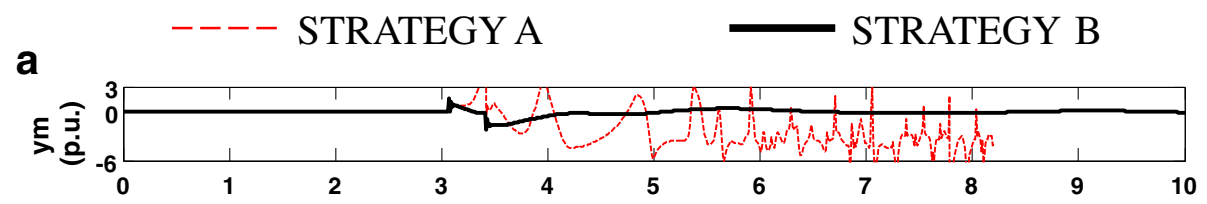

b

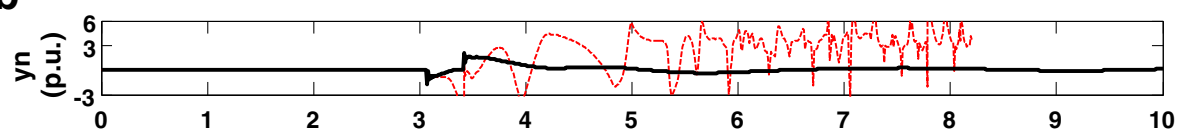

C

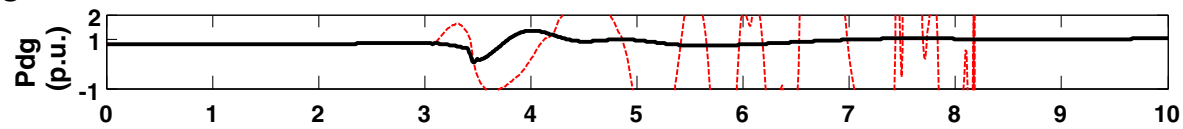

d

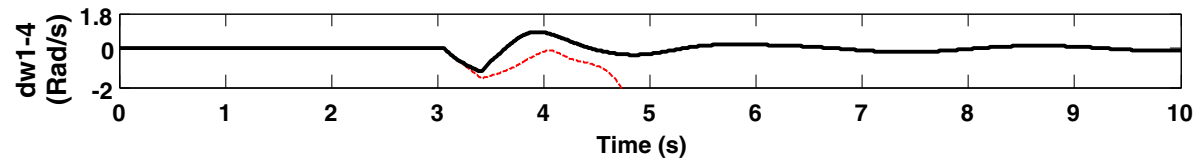

Fig. 11 The response of the proposed and conventional controls of the admittance model of the UPFC for a three phase to ground fault at time $t=3.05 \mathrm{~s}$ (operating point ' $\mathrm{D}$ ') on the bus 7 of the test system as shown in Fig. 5, with a higher penetration of the DFIG wind farm which is subjected to a variable wind speed (Fig. 6), where, a the admittance of the UPFC at bus ' $m$ ' in p.u., $\mathbf{b}$ the admittance of the UPFC at bus ' $n$ 'in p.u., c the active power injection of the DFIG (p.u.), and $\mathbf{d}$ the interarea oscillation between the generators ' 1 ' and ' 4 ' in Rad/s, respectively 


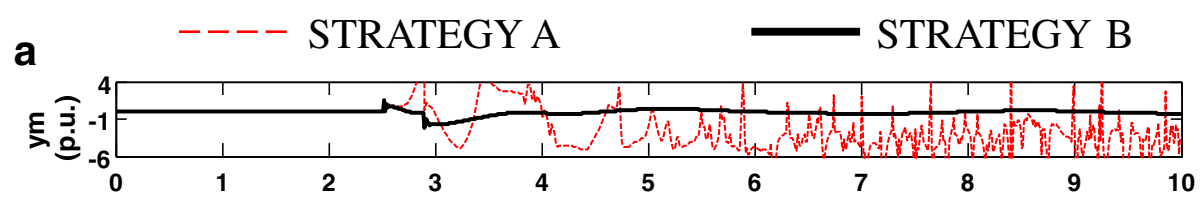

b

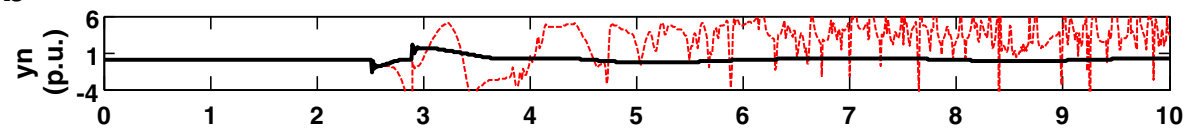

C

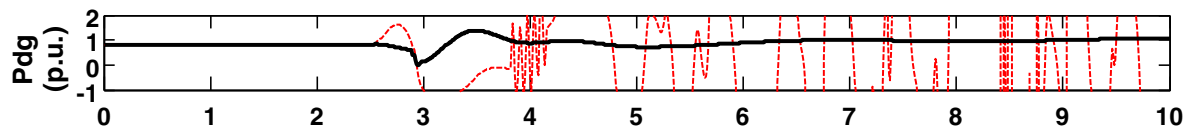

d

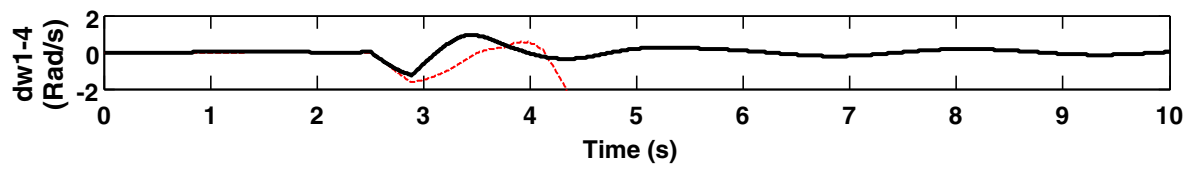

Fig. 12 The response of the proposed and conventional controls of the admittance model of the UPFC for a three phase to ground fault at time $t=2.5 \mathrm{~s}$ (operating point ' $C$ ') on the bus 7 of the test system as shown in Fig. 5, with a higher penetration of the DFIG wind farm which is subjected to a variable wind speed (Fig. 6), where, a the admittance of the UPFC at bus ' $m$ ' in p.u., b the admittance of the UPFC at bus ' $n$ 'in p.u., c the active power injection of the DFIG (p.u.), and $\mathbf{d}$ the interarea oscillation between the generators ' 1 ' and ' 4 ' in Rad/s, respectively

10, 11 and 12, respectively. Analogous to the previous section, in order to evaluate the $T_{C C L}$ (see Appendix for details), the performance of the proposed as well as conventional controls of the AM of the UPFC has been constantly observed by gradually increasing the duration of fault' $t_{f}$ ' for all the cases discussed in this case. Similar observations as in case of previous case has been observed in this case. For the particular cases illustrated in these figures, it is observed that for the fault duration resembling the $T_{C C L}$ for the conventional PI control (where the generators loose synchronism in the post fault region), the performance of the proposed AFITSMPC for the AM of the UPFC is very much stable there is drastic improvement in the $T_{C C L}$, which is evident in the subfigures (a) to (d) in the Figs. 9, 10, 11 and 12, respectively.

A detailed quantitative analysis of the proposed STRATEGY B, i.e., Adaptive Fractional Integral terminal sliding mode Power control (AFITSMPC) for the AM of the UPFC over the conventional STRATEGY A, for demonstrating its (proposed controller) robustness in

Table 1 Critical Clearing time for the conventional and proposed controllers subjected to Lower penetration of DFIG Power

\begin{tabular}{llll}
\hline $\begin{array}{l}\text { Operating } \\
\text { Points }\end{array}$ & $\begin{array}{l}T_{\text {CCL for STRATEGY A }} \\
\text { in ms }\end{array}$ & $\begin{array}{l}T_{\text {CC }} \text { for STRATEGY B } \\
\text { in ms }\end{array}$ & $\begin{array}{l}\text { Improvement in } T_{C C L} \\
\text { for STRATEGY B in ms }\end{array}$ \\
\hline A & 498 & 514 & 16 \\
B & 514 & 523 & 09 \\
C & 485 & 504 & 19 \\
$D$ & 507 & 521 & 14 \\
\hline
\end{tabular}

enhancing the transient stability of the DFIG wind farm penetrated two area four machine power system have been illustrated in Tables 1 and 2 respectively. Form these tables, it illustrates the $T_{C C L}$ for both the conventional and proposed controls as well as the improvement in the $T_{C C L}$ for the proposed control for all the cases discussed in this case, with the lower and higher penetration levels of the DFIG, respectively.

The improvement in $T_{C C L}$ ranges between $9 \mathrm{~ms}-$ $19 \mathrm{~ms}$ in the lower DFIG wind power penetration case, where as it lies between $5 \mathrm{~ms}-23 \mathrm{~ms}$ for the higher DFIG wind power penetration case. Thus as the proposed AFITSMPC for the AM of the UPFC illustrates an improved result in terms of damping out the oscillations between the generators of the multimachine power system for a number of intrinsic operating conditions, hence it guarantees the robustness of the method and also the applicability of the method in real time applications (which is considered as a future work in this paper).

Table 2 Critical Clearing time for the conventional and proposed controllers subjected to Higher penetration of DFIG Power

\begin{tabular}{llll}
\hline $\begin{array}{l}\text { Operating } \\
\text { Points }\end{array}$ & $\begin{array}{l}T_{\text {CCLfor STRATEGY A }} \text { in ms } \\
\text { A }\end{array}$ & $\begin{array}{l}T_{C C L} \text { for STRATEGY B B } \\
\text { in ms }\end{array}$ & $\begin{array}{l}\text { Improvement in } T_{C C L} \\
\text { for STRATEGY B in ms }\end{array}$ \\
\hline B & 391 & 414 & 23 \\
C & 411 & 426 & 15 \\
$D$ & 387 & 392 & 05 \\
\hline
\end{tabular}




\section{Discussion}

It is observed that from previous two subsections and Figs. 7, 8, 9, 10, 11 and 12, that after the initiation of disturbance, the simulation of the overall model (Fig. 5), illustrates some low frequency oscillations (as in case of the interarea oscillation between the generators 1 and 4) which is uncontrollable. On the contrary, the above simulation with the proposed AFITSMPC for the AM of the UPFC, i.e., STRATEGY B, also exhibits some low frequency oscillation (as in case of the interarea oscillation between the generators 1 and 4), which deviates approximately between -2 and $2 \mathrm{Rad} / \mathrm{S}$. But in spite of it, the active power or the reactive power based AFITSMPC control of an AM of the UPFC considerably damps out the respective inter-area low-frequency oscillations exhibited by the network. In addition, the DFIG wind farm is also equipped with the PI control mechanism on active and reactive powers for both the rotor side as well as grid side converters [21], which also boosts up in damping the above low frequency interarea oscillations [22]. It is also observed that, [22] illustrates a method by which the low-frequency oscillation modes of the presented power system can be calculated through a lowfrequency oscillation modal analysis combined with the dynamic small signal mathematical models of DFIG wind turbines and synchronous generators, including their eigenvalues, oscillation frequencies, and damping ratios. This is an important and interesting topic which will be given full consideration as a future work.

In addition, the adaptive nature of the controller gains of the proposed AFITSMPC for the AM of the UPFC, is very much significant in quickly stabilizing the admittance model of the UPFC where the DFIG wind farm in the multimachine power system has been subjected to fixed as well as sporadic wind profile. In all the cases, there has been a significant improvement in the interarea oscillations exhibited by the MPN by the strategy B, which is justified in subfigure (d) of the Figs. 6, 7, 8, 9, 10 and 11, respectively. The $T_{C C L}$ for both the strategy A and B have been tabulated which justifies its improvement for proposed STRATEGY $B$ for almost all the cases illustrated in this section. Further it is observed that, with the increase in penetration level of the DFIG wind farm, there is a significant increase in the maximum overshoots of the $P_{d g}$. In spite of this, the proposed AFITSMPC for the AM of the UPFC, in comparison to the conventional PI controller, is very much significant and robust to enhance the stability of the MPN, subjected to both the higher and lower level DFIG wind farm penetration with fixed as well as sporadic wind profiles subjected to different intrinsic operating conditions.

\section{Conclusion}

An adaptive fractional integral terminal sliding mode power control strategy of the admittance model (AM) of the UPFC, in order to damp out the oscillation between the generators in a DFIG wind farm penetrated multimachine power system is proposed in this paper. Taking the critical clearance time $\left(T_{C C L}\right)$ as the basis, the performance of the conventional PI is compared with the proposed AFITSMPC for the AM of the UPFC. It is observed that the adaptive nature of the proposed strategy $B$ is very much significant in maintaining the synchronism between the generators in the multimachine system for a larger period of time $\left(T_{C C L}\right)$, which is evident by improvement in TCCL for the proposed strategy for almost all the case studies illustrated in the paper. It is also observed that the proposed AFITSMPC for the AM of the UPFC significantly stabilizes the active power output of the DFIG wind farm. This improves the electric power of the nearby generators, which subsequently improves (diminish) the irrespective rotor angle deviations and hence leads to the stability enhancement of the multimachine power system. The proposed controllers for the UPFC has been tested for the stability enhancement of the MPN for higher and lower penetrations of the DFIG power, at various operating points, where the DFIG wind farm has been subjected to a fixed as well as a sporadic wind profile, respectively. It is observed that, with an increase in penetration level of the DFIG, the oscillations shown by its active power in the post fault region increases. In spite of this, the proposed controller for the AM of the UPFC has outperformed the conventional one, by inheriting larger $T_{C C L}$, for the DFIG penetrated multimachine system, under a number of intrinsic operating conditions. This has been analyzed in the simulation and result section, where the outputs shown are satisfactory and vindicates the superiority of the proposed controller.

\section{Appendix}

a) The dynamic model of the $k^{\text {th }}$ synchronous generator [19], $(k=1,2, . ., 6)$ is signified as:

$$
\left.\begin{array}{l}
\dot{\delta}_{k}=\omega_{k}-\omega_{k 0} \\
\omega_{k}=\xi_{1}\left[p_{M k}-p_{E k}\right] \\
\dot{e}_{Q k}^{\prime}=\xi_{2}\left[\Delta e_{f d k}-\left(X_{d k}-X_{d k}^{\prime}\right) I_{d k}+e_{f d k 0}-e_{q k}^{\prime}\right] \\
\Delta \dot{e}_{f d k}=\xi_{3}\left[K_{e k}\left(V_{t k r e f}-V_{t k}+\kappa_{k}\right)-\Delta e_{f d k}\right]
\end{array}\right\}
$$

where ' $\delta_{k}$ ' denotes the angular position of rotor, ' $\omega_{k}$ ' and ' $\omega_{k}{ }^{\prime}$ ' are the real and reference angular rotor speed, $\mathrm{p}_{M k}$ and $p_{E k}$ are the mechanical and electrical power output of the $k^{\text {th }}$ synchronous generator, respectively. $X_{d k}, X_{q k}$, $X_{d k}^{\prime}$ and $X_{q k}^{\prime}$ denotes the $d q$ - axis synchronous and transient reactance's of the $k^{\text {th }}$ synchronous generator, respectively. $E_{f d i}$ is the transient voltage, $V_{t k r e}$ fand $V_{t k}$ are 
the reference and actual terminal voltage of the $k^{\text {th }}$ synchronous generator, respectively. $e_{d i}^{\prime}, e_{q i}^{\prime}, I_{d i}^{\prime}$, and $I_{q i}^{\prime}$ denotes the dq- axis terminal current and voltage of the $k^{\text {th }}$ synchronous generator, respectively.

Main parameters of synchronous generator are as follows:

Stator leakage reactance $(\times 1)$ : 0.2 p.u., Stator resistance (Rs):

0.0025 p.u., Synchronous reactance of $\mathrm{d}$-axis $\left(x_{d}\right): 1.8$ p.u., Transient reactance of d-axis $\left(x_{d}^{\prime}\right): 0.3$ p.u., Sub transient reactance of d-axis $\left(x_{d}^{\prime \prime}\right): 0.25$ p.u., Synchronous reactance of q-axis $\left(x_{q}\right): 1.7$ p.u., Transient reactance of q-axis $\left(x_{q}^{\prime}\right)$ : 0.55 p.u., Sub-transient reactance of q-axis $\left(x_{q}^{\prime \prime}\right): 0.25$ p.u., Transient time constant of d-axis $\left(\mathrm{T}_{d}^{\prime}\right): 8 \mathrm{~s}$, Sub-transient time constant of $\mathrm{d}$-axis $\left(\mathrm{T}_{d}^{\prime \prime}\right): 0.03 \mathrm{~s}$, Transient time constant of q-axis $\left(\mathrm{T}_{q}^{\prime}\right)$ : $0.4 \mathrm{~s}$, Sub-transient time constant of q-axis $\left(\mathrm{T}_{q}^{/ /}\right): 0.05 \mathrm{~s}$.

Main parameters of the aggregated DFIG-based wind farm:

Rated voltage: $690 \mathrm{~V}$, Stator resistance $R_{s}: 0.00706$ p.u., Stator leakage reactance $X_{s}: 0.171$ p.u., Rotor resistance $R_{r} 0.005$ p.u., Rotor leakage reactance $X_{r l}$ : 0.156 p.u., Magnetizing reactance $X_{m}: 2.9$ p.u., Inertia constant of equivalent generator $H_{g}: 0.94 \mathrm{~s}$, Inertia constant of equivalent wind turbine $H_{w}: 4.93 \mathrm{~s}$, Torsional stiffness of equivalent drive-train $K_{s}: 0.5$ p.u./ el.rad. $r_{I}=0.04, x_{I}=0.2, c_{d c}=0.1$.

Wind Turbine data: $\rho_{\text {air }}=1.225 \mathrm{Kg} / \mathrm{m}^{3}, r_{\text {blade }}=58.6 \mathrm{~m}$, $\omega_{t}=0.8, \omega_{S}=1$,

$$
\begin{gathered}
c_{P P}=\mu_{1}{ }^{*}\left[\frac{\mu_{2}}{\lambda_{P P}+\beta_{A I R} \mu_{8}}-\frac{\mu_{2} \mu_{9}}{\beta_{A I R}^{3}+1}\right. \\
\left.-\mu_{3} \beta_{A I R}-\mu_{4} \beta_{A I R}{ }^{\mu_{5}}-\mu_{6}\right] * e^{\frac{\mu_{2}}{\lambda_{P P}+\beta_{A I R} \mu_{8}}}+\mu_{10}
\end{gathered}
$$

where $\mu_{1}=0.22, \mu_{2}=116, \mu_{3}=0.4, \mu_{4}=0, \mu_{5}=0, \mu_{6}=5, \mu_{7}=12.5$, $\mu_{8}=0.08, \mu_{9}=0.035 \mathrm{and} \mu_{10}=0$.

The values of the parameter of the proposed controller:

$$
\begin{aligned}
\alpha_{1} & =0.1, \alpha 2=1.0, \beta_{1}=0.6, \beta_{2}=0.6, \beta_{\text {ProbV }} \\
& =0.1, \beta_{\text {QrobV }}=8, \beta_{\text {ProbA }}=0.1, \beta_{\text {QrobA }}=10 .
\end{aligned}
$$

The values of the parameter of conventional PI controller for DFIG:

$$
K_{P d r}=0.1, K_{I d r}=150, K_{\text {Pid }}=0.5, K_{\text {Iiq }}=200 .
$$

The values of the parameter of conventional PI controller for AM of UPFC:

$$
K_{\text {Pym }}=1, K_{\text {Iym }}=1150, K_{\text {Pyn }}=4.35, K_{\text {Iyn }}=1200 .
$$

\section{Authors' contributions}

Author RKP designed the Adaptive fractional sliding mode algorithm for the DFIG wind farm with UPFC along with some simulations. Author PK.Dash conceived the original problem for detailed study along with results verification and coordition of the various sections of the manuscript.. Author S.P.Mishra did some simulations and provided data and took part in revising the paper.. All authors read and approved the final manuscript.

\section{Competing interests}

The authors declare that they have no competing interests." Also no fund is received from any financial or non-financial organization.

\section{Author details}

'Siksha O Anusandhan University, Khandagiri Square, Bhubaneswar, Odisha 751030, India. ' $\mathrm{GMR}$ Institute of Technology, Rajam, Andhra Pradesh 532127, India.

Received: 22 August 2017 Accepted: 31 January 2018

Published online: 30 March 2018

\section{References}

1. Mitra, A., \& Chatterjee, D. (2016). Active power control of DFIG-based wind farm for improvement of transient stability of power systems. IEEE Transactions on Power Systems, 31(1), 82-93.

2. Lei, X., Lerch, E. N., \& Povh, D. (2001). Optimization and coordination of damping controls for improving system dynamic performance. IEEE Transactions on Power Systems, 16(3), 473-480.

3. Wang, H. (2000). A unified model for the analysis of FACTS devices in damping power system oscillations. III. Unified power flow controller. IEEE Transactions on Power Delivery, 15(3), 978-983.

4. Noroozian, M., Angquist, L., Ghandhari, M., \& Andersson, G. (1997). Improving power system dynamics by series-connected FACTS devices. IEEE Transactions on Power Delivery, 12(4), 1635-1641.

5. Azbe, V., Gabrijel, U., Povh, D., \& Mihalic, R. (2005). The energy function of a general multimachine system with a unified power flow controller. IEEE Transactions on power systems, 20(3), 1478-1485.

6. Zadehbagheri, M., Ildarabadi, R., \& Nejad, M. B. (2014). Review of the UPFC different models in recent years. International Journal of Power Electronics and Drive Systems, 4(3), 343-355.

7. Dash, P. K., Morris, S., \& Mishra, S. (2004). Design of a nonlinear variable-gain fuzzy controller for FACTS devices. IEEE transactions on control systems technology, 12(3), 428-438.

8. Zhang, X. P., Rehtanz, C., \& Pal, B. (2012). Flexible AC transmission systems: modelling and control. New York: Springer, Science \& Business Media, ISBN: 978-3-642-28240-9.

9. Mishra, S., Dash, P. K., \& Panda, G. (2000). TS-fuzzy controller for UPFC in a multimachine power system. IET Gener Transm Distrib, 147(1), 15-22.

10. Nayeripour, M., Narimani, M. R., Niknam, T., \& Jam, S. (2011). Design of sliding mode controller for UPFC to improve power oscillation damping. Applied Soft Computing, 11(8), 4766-4772.

11. Morris, S., Dash, P. K., \& Morris, E. (2006). A PSO-based neuro-sliding mode controller for the stability enhancement of power systems with UPFC 5th World Scientific and Engineering Academy and Society (WSEAS) International Conference on Circuits, Systems, Electronics, Control \& Signal Processing (pp. 122-122).

12. Dadras, S., \& Momeni, H. R. (2012). Fractional terminal sliding mode control design for a class of dynamical systems with uncertainty. Communications in Nonlinear Science and Numerical Simulation, 17(1), 367-377.

13. Shotorbani, A. M., Ajami, A., Zadeh, S. G., Aghababa, M. P., \& Mahboubi, B. (2014). Robust terminal sliding mode power flow controller using unified power flow controller with adaptive observer and local measurement. IET Generation, Transmission \& Distribution, 8(10), 1712-1723.

14. Huang, H., \& Chung, C. Y. (2012). Coordinated damping control design for DFIG-based wind generation considering power output variation. IEEE Transactions on Power Systems, 27(4), 1916-1925.

15. Ghosh, S., Kamalasadan, S., Senroy, N., \& Enslin, J. (2016). Doubly fed induction generator (DFIG)-based wind farm control framework for primary frequency and inertial response application. IEEE Transactions on Power Systems, 31(3), 1861-1871.

16. Miao, Z., Fan, L., Osborn, D., \& Yuvarajan, S. (2009). Control of DFIG-based wind generation to improve interarea oscillation damping. IEEE Transactions on Energy Conversion, 24(2), 415-422.

17. Zhu, X., Genton, M. G., Gu, Y., \& Xie, L. (2014). Space-time wind speed forecasting for improved power system dispatch. TEST, 23(1), 1-25. 
18. Pahn, T., Rolfes, R., \& Jonkman, J. (2017). Inverse load calculation procedure for offshore wind turbines and application to a 5-MW wind turbine support structure. Wind Energy, 20(7), 1171-1186.

19. Kundur, P. (1994). In N. J. Balu \& M. G. Lauby (Eds.), Power system stability and control. New York: McGraw-hill.

20. Martins, F. G. (2005). Tuning PID controllers using the ITAE criterion International Journal of Engineering Education, 21(5), 867-873.

21. Patnaik, R. K., \& Routray, S. K. (2015). Damping of interarea oscillations of a wind farm based multimachine power system using an unified power flow controller. Bhubaneswar: IEEE Power, Communication and Information Technology Conference (PCITC) (pp. 458-464). IEEE.

22. Li, H., Liu, S., Ji, H., Yang, D., Yang, C., Chen, H., Zhao, B., Hu, Y., \& Chen, Z. (2014). Damping control strategies of inter-area low-frequency oscillation for DFIG-based wind farms integrated into a power system. International Journal of Electrical Power \& Energy Systems, 61, 279-287.

\section{Submit your manuscript to a SpringerOpen ${ }^{\odot}$ journal and benefit from:}

- Convenient online submission

- Rigorous peer review

- Open access: articles freely available online

- High visibility within the field

- Retaining the copyright to your article

Submit your next manuscript at $>$ springeropen.com 